\title{
Is stamceltherapie voor orthopedische aandoeningen bij de hond reeds inzetbaar?
}

\author{
${ }^{1}$ E. de Bakker, ${ }^{1}$ M. Dallago, ${ }^{1}$ B. Van Ryssen, ${ }^{2}$ E. Meyer \\ ${ }^{1}$ Vakgroep Medische Beeldvorming van de Huisdieren en Orthopedie van de Kleine Huisdieren \\ ${ }^{2}$ Vakgroep Farmacologie, Toxicologie en Biochemie \\ Salisburylaan 133 \\ B-9820 Merelbeke
}

evelien.debakker@ugent.be

\section{INLEIDING}

\section{Situering van stamceltherapie in de diergenees- kunde}

In navolging van de humane geneeskunde is de interesse in stamceltherapie ook in de diergeneeskunde sterk toegenomen (Fortier en Travis, 2011; de Bakker et al., 2013). Door de toenemende media-aandacht is stamceltherapie voor velen zelfs een bekende term geworden. In de diergeneeskunde is de toepassing van stamceltherapie voornamelijk gericht op orthopedische aandoeningen bij paarden en honden, aangezien klassieke medicamenteuze en chirurgische therapieën voor vele bot-, kraakbeen- en ligamenteuze aandoeningen vaak niet resulteren in een volledig functioneel herstel (de Bakker et al., 2013; De Schauwer et al., 2013). Wereldwijd zijn er reeds verschillende stamcelproducten voor orthopedische indicaties bij de hond op de markt. Vele "feel-good" filmpjes en anekdotische getuigenissen van eigenaars zijn te vinden in de media ( http://fat-stem.be/wp-content/ uploads/2014/02/artikel-Vlaamse-Jager-Aug-2013. pdf, http://www.usatoday.com/story/news/nation/2014/02/05/pets-stem-cell-treatment/5224363/). Echter, het aantal objectieve wetenschappelijke studies van stamceltherapie bij de hond blijft tot op heden beperkt (de Bakker et al., 2013). Bovendien zijn meerdere sleutelaspecten van caniene stamcellen nog deels onbekend, waaronder hun eenduidige karakterisering, exacte werkingsmechanisme, optimale dosis voor iedere indicatie, ideale toedieningsroute en -tijdstip en de veiligheid (neveneffecten op korte en lange termijn) (de Bakker et al., 2013). Hierdoor blijft de vraag bestaan of stamceltherapie echt een langetermijnmeerwaarde biedt voor de behandeling van orthopedische aandoeningen bij de hond.

\section{WAT IS EEN STAMCEL?}

Een stamcel is een ongedifferentieerde cel die zichzelf kan vernieuwen door replicatie en kan differentiëren naar verschillende cellijnen behorende tot de drie kiemlagen (Fortier, 2005) (Figuur 1). Een totipotente stamcel kan een volledig organisme maken, een eigenschap die voorbehouden is aan de zygote tot aan het 8-cellig stadium van de morula. Pluripotente stamcellen kunnen weefsels vormen afkomstig van alle embryonale kiemlagen (ecto-, endo- en mesoderm), terwijl multipotente stamcellen aanleiding kunnen geven tot een beperktere subset van cellijnen (Fortier, 2005). Een stamcel kan grofweg ingedeeld worden in embryonaal en adult, afhankelijk van het ontwikkelingsstadium waarvan zij verkregen is. Een embryonale stamcel is afkomstig van de binnenste celmassa van de blastocyst, wat het pre-implantatie stadium is van een gemiddeld één week oud (afhankelijk van het species) embryo (Fortier, 2005). Een adulte stamcel is afkomstig van een postnataal organisme, waarvan de hematopoïetische stamcellen uit het beenmerg de meest bekende zijn. Deze hematopoïetische stamcellen kunnen differentiëren naar alle bloedcellen van het hematolymfatisch systeem, zoals erytrocyten, lymfocyten en neutrofielen (Fortier, 2005). Deze stamcellen zijn reeds lang bekend in hun toepassing van beenmergtransplantatie ter behandeling van diverse beenmergaandoeningen, zoals leukemie (Fortier, 2005). Anderzijds kunnen adulte stamcellen verkregen worden uit stromaal weefsel van hetzij ecto- (i.e. huid, tanden, haarfollikel), hetzij endo- (i.e.

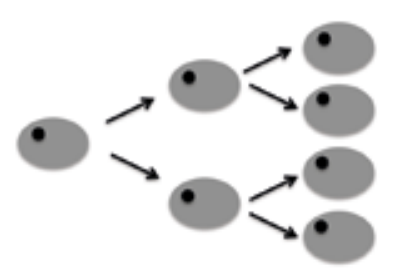

Replicatie

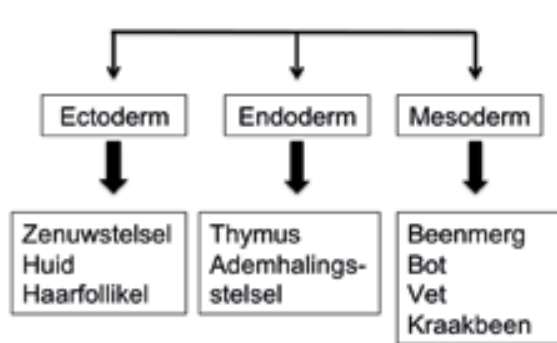

Differentiatie

Figuur 1. Overzicht van de belangrijkste kenmerken van een stamcel: vernieuwing via replicatie en differentiatie naar verschillende celtypes behorend tot de drie kiemlagen. 
thymus, intestinaal weefsel), hetzij mesodermale oorsprong (i.e. beenmerg, vet, spier, bot) (Fortier, 2005).

Dit laatste type van adulte stamcellen wordt ook wel mesenchymale stamcellen (MSC) genoemd en wordt therapeutisch het meest frequent toegepast (de Bakker et al. 2013).

Wegens belangrijke nadelen bij het gebruik van embryonale stamcellen, zoals ethische bezwaren tegen het gebruik van (humane) embryo's en het grote risico op de ontwikkeling van teratomen, worden voornamelijk adulte (mesenchymale) stamcellen gebruikt in de veterinaire orthopedie (Fortier, 2005).

\section{WAT ZIJN DE BRONNEN VAN CANIENE MESENCHYMALE STAMCELLEN?}

In de meeste experimentele en klinische studies bij de hond worden MSC gebruikt afkomstig van beenmerg of vet, aangezien deze bronnen het beste gekarakteriseerd en relatief vergelijkbaar zijn (Fortier en Travis 2011; Kisiel et al., 2012; Takemitsu et al., 2012; de Bakker et al., 2013). Er moet voor beide een onderscheid gemaakt worden tussen enerzijds de nietgeëxpandeerde, autologe producten (i.e. beenmergconcentraat en vet-afgeleide stromale vasculaire fractie) en anderzijds de cultuur-geëxpandeerde autologe of allogene producten (i.e. beenmerg- en vet-afgeleide MSC) (Borjesson and Peroni 2011). De belangrijkste voordelen van niet-geëxpandeerde cellulaire producten zijn de heterogeniteit van de celpopulatie en de mogelijkheid om het product direct te injecteren zonder nood aan voorafgaande celcultuur (Borjesson en Peroni 2011; Fortier en Travis 2011). Cultuur-geexpandeerde cellen zijn dan weer sterk verrijkt met MSC, maar de cultuur neemt tot drie weken tijd in beslag, wat hun gebruik voor de behandeling van acute letsels onmogelijk maakt (Borjesson en Peroni, 2011).

Naast het gebruik van autologe caniene MSC is er meer en meer interesse in het gebruik van allogene caniene MSC. Waar autologe MSC als voordeel hebben dat ze relatief veilig zijn omdat het product ingespoten in het dier, afkomstig is van weefsel van het dier zelf, hebben ze als nadeel dat een acute behandeling uitgesloten is (Figuur 2). Bovendien is commercialisering van autologe MSC onmogelijk, aangezien het product enkel geproduceerd wordt voor één bepaald dier. Allogene stamcellen worden daarentegen verkregen uitgaande van één zorgvuldig geselecteerde donorhond en kunnen nadien toegediend worden aan eender welke hond (Figuur 3). Hierdoor is productie op grote schaal mogelijk en is de therapie ook direct beschikbaar als "off-the-shelf product". Mogelijke nadelen van allogene MSC zijn het overdragen van ziekten en het optreden van een afweerreactie bij de gastheer. Echter, net zoals in de humane geneeskunde worden er in de diergeneeskunde in stijgende mate nu ook strenge veiligheidscontroles uitgevoerd tijdens het ontwikkelingsproces van deze allogene MSC (Jacobs et al., 2013a). Bovendien hebben meerdere studies bij mens en paard reeds aangetoond dat stamcel-

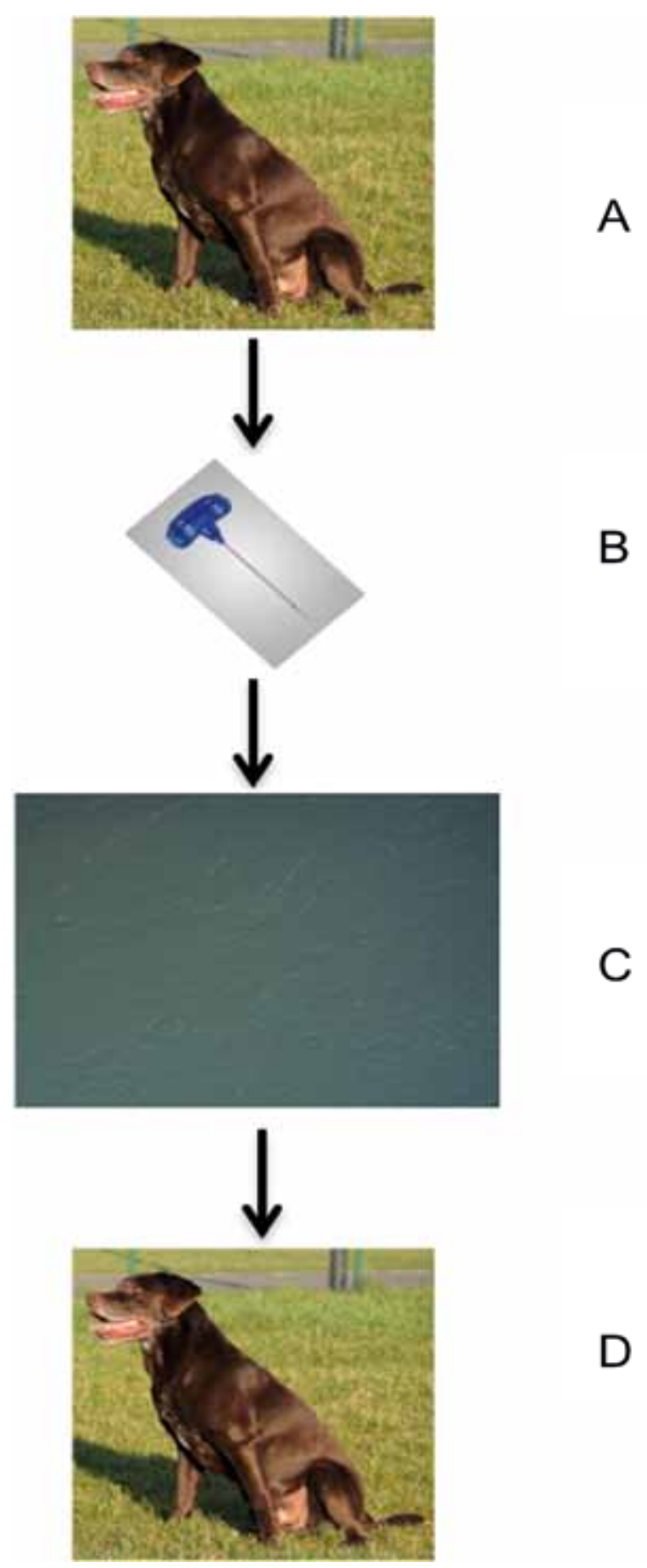

Figuur 2. Overzicht van de procedure van autologe beenmerg-afgeleide, caniene MSC. Een beenmergstaal wordt afgenomen bij de hond (A) met een jamshidibiopsienaald (B). Dit staal wordt verwerkt in het labo tot caniene MSC na een aantal weken op cultuur (C). Vervolgens worden de caniene MSC geïnjecteerd in dezelfde hond (D).

len wegens hun immunomodulerend effect hypo- tot zelfs niet-immunogeen zijn (Barry en Murphy 2004, Carrade et al., 2011).

Beenmerg-afgeleide MSC hebben in vergelijking met andere types MSC een grotere capaciteit om te differentiëren naar weefsel van het musculoskeletaal stelsel, wat momenteel de belangrijkste indicatie is 


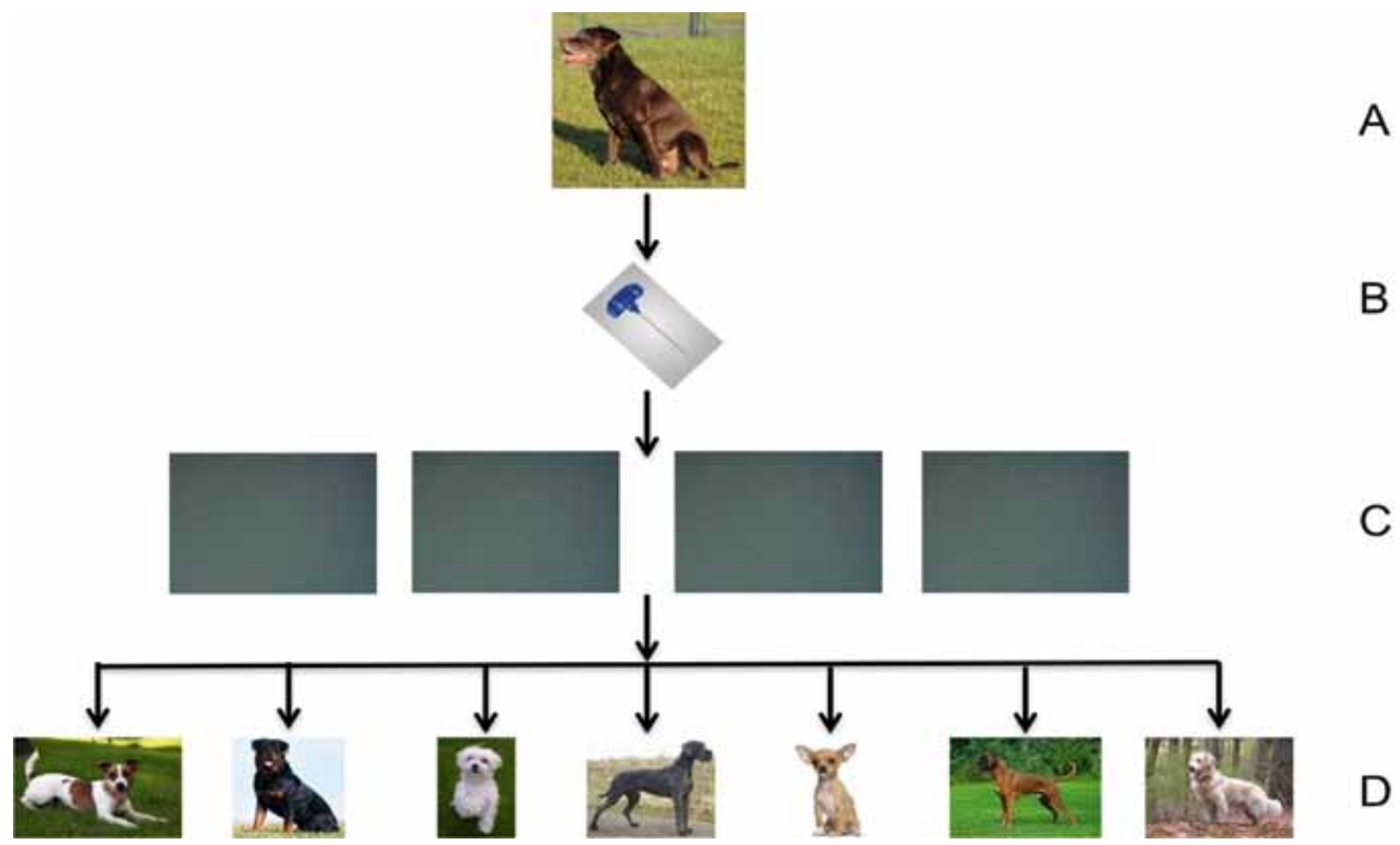

Figuur 3. Overzicht van de procedure van allogene, beenmerg-afgeleide, caniene MSC. Bij een zorgvuldig geselecteerde donorhond wordt met een jamshidi-biopsienaald beenmerg afgenomen $(A+B)$. Dit staal wordt verwerkt in het labo, geëxpandeerd op cultuur en ingevroren per dosis (C). Wanneer een hond zich aanbiedt met een orthopedische aandoening die in aanmerking komt voor stamceltherapie, kan het in voorraad aanwezig stamcelproduct onmiddellijk worden toegediend (D).

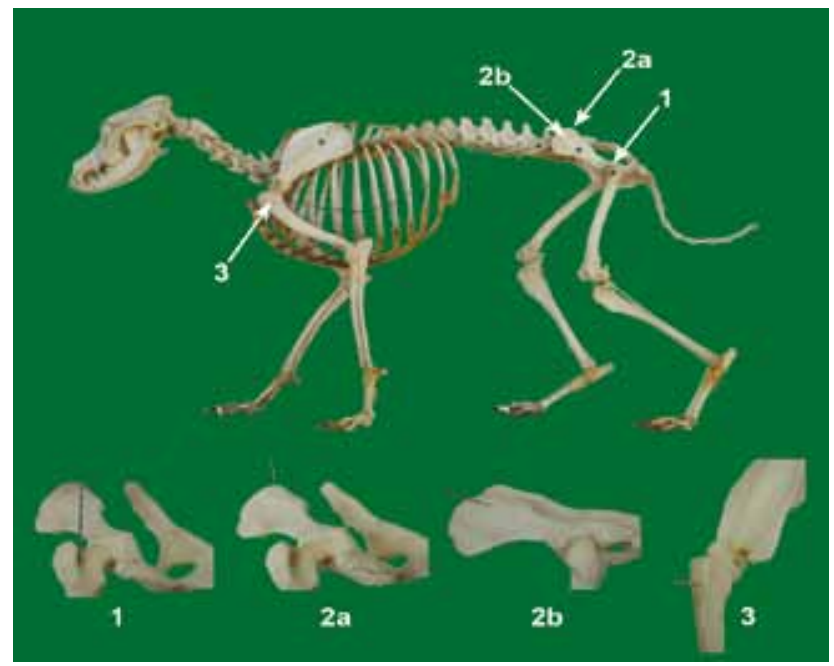

Figuur 4. Overzicht van de toegankelijke punctieplaatsen van het beenmerg bij de hond (Naar de Bakker et al., 2013). 1. Benadering van de proximale femur. De naald is geplaatst in de fossa trochanterica tussen de trochanter minor en major. 2a. Dorsale benadering van de iliumvleugel aan de dorsale rand. De naald is parallel gericht met de lange as van de iliumvleugel. Voor deze benadering wordt de hond het beste gepositioneerd in sternale decubitus. $2 b$. Laterale benadering van de iliumvleugel ongeveer 1 cm onder de dorsale rand. De richting van de naald is nu loodrecht op de iliumvleugel. Voor deze benadering wordt de hond het beste in laterale decubitus gepositioneerd. 3 . Benadering van de proximale humerus, net onder het tuberculum majus van de humerus. De naald wordt ingebracht onder een hoek van $45^{\circ}-90^{\circ}$ ten opzichte van een lijn parallel met de lange as van de humerus. voor regeneratieve geneeskunde bij de hond (de Bakker et al., 2013, Marx et al., 2015). Echter, het verkrijgen van beenmerg kan bij honden soms een uitdaging vormen (Abrams-Ogg et al., 2012). Bovendien worden de honden voor deze procedure ook het beste onder algemene anesthesie gebracht (Takemitsu et al., 2012). Bij de hond wordt beenmerg voornamelijk geaspireerd uit de proximale humerus, de proximale femur of de dorsale iliumvleugel met behulp van een 15- of 16-gauge-jamshidi-biopsienaald (Bruder et al., 1998; Crovace et al., 2008; de Bakker et al., 2013) (Figuur 4).

Recent wordt ook vet beschouwd als een zeer aantrekkelijke bron van MSC, voornamelijk wegens het gemak van staalname en de beschikbaarheid van vetweefsel op verschillende plaatsen in het lichaam (Stewart en Stewart, 2011). Bij de hond kan vetweefsel verzameld worden via een eenvoudige biopsie- of een aangepaste liposuctieprocedure, of bij routinechirurgie (Vieira et al., 2010). Bovendien levert vet een hoge initiële celopbrengst op en vet-afgeleide MSC vertonen in vitro zowel een robuuste proliferatiecapaciteit als sterke immunomodulerende eigenschappen (Stewart en Stewart, 2011).

\section{STAALVERWERIKING TOT INJECTEERBARE CANIENE MESENCHYMALE STAMCELLEN}

Het beenmerg- of vetstaal bevat naast MSC diverse andere mononucleaire cellen, rode bloedcellen, mature adipocyten, serum, etc. Studies hebben aan- 
getoond dat het aandeel van MSC in beenmerg ten opzichte van de totale populatie van gekernde cellen zeer klein is, namelijk slechts $0,001 \%$ tot $0,01 \%$ (Fortier en Travis, 2011). In vetweefsel is dit beduidend hoger, namelijk 2\% tot 10\% (Marx et al., 2015). Het is dus noodzakelijk om uit het afgenomen beenmerg- of vetstaal MSC te isoleren en vervolgens aan te rijken. Een isolatieprotocol voor MSC uit beenmerg of vet bij de hond is door verschillende onderzoeksgroepen op punt gesteld (Gimble en Guilak, 2003; Neupane et al., 2008; Vieira et al. 2010; Kisiel et al., 2012; Takemitsu et al., 2012; Marx et al., 2015).

Voor beenmerg wordt het staal in fracties gescheiden met behulp van een densiteitsgradiënt, waarbij verschillende lagen verkregen worden (Takemitsu et al., 2012; Marx et al., 2015) (Figuur 5). Enkel met de mononucleaire fractie wordt verder gewerkt. Deze dunne laag van mononucleaire cellen wordt geaspireerd en na een wasprocedure worden er ongeveer 1 miljoen cellen per ml op cultuur gezet bij $37^{\circ} \mathrm{C}$ en $5 \%$ $\mathrm{CO}^{2}$. Het cultuurmedium, bestaande uit "Dulbecco's modified eagle's medium" aangevuld met $10 \%$ foetaal bovien serum, antibiotica en antimycotica, moet vervolgens tweemaal per week vervangen worden. Wanneer $70 \%$ tot $80 \%$ van de bodem van de cultuurfles bedekt is met een laag cellen, worden de cellen gesplitst en over nieuwe cultuurflessen verdeeld voor verdere expansie; ofwel worden ze ingevroren (Kisiel et al., 2012; Takemitsu et al., 2012).

In tegenstelling tot beenmerg moet vetweefsel eerst mechanisch worden fijngemaakt en verteerd worden met behulp van collagenase (Takemitsu et al., 2012; Marx et al., 2015). De verkregen "digest" wordt gecentrifugeerd en nadien gewassen, waarbij de mature adipocyten verwijderd worden. De overgebleven stromale vasculaire fractie kan nu ook op cultuur gezet worden. De te volgen stappen voor het aanmaken van een cultuur zijn vergelijkbaar met die voor beenmerg (Neupane et al., 2008; Takemitsu et al., 2012; Marx et al. 2015).

Nadat de diverse stappen succesvol doorlopen zijn moet aangetoond worden dat het effectief om MSC gaat (karakterisering). Voor humane stamcellen heeft de "International Society of Cellular Therapy" (ISCT) de eigenschappen waaraan humane MSC moeten voldoen als volgt gedefinieerd: 1) kleven aan plastic in cultuur, 2) differentiatie naar tenminste drie verschillende cellijnen in vitro, namelijk osteogeen, chondrogeen en adipogeen, 3) expressie van bepaalde celoppervlakte-antigenen in combinatie met het ontbreken van expressie van andere specifieke celoppervlakteantigenen (Dominici et al., 2006; De Schauwer et al., 2011). Bij de hond zijn er momenteel in beperkte mate ook data beschikbaar, waarbij gebruik wordt gemaakt van dezelfde criteria als bij de mens (Martinello et al., 2010; Vieira et al., 2010; Takemitsu et al., 2012; Screven et al., 2014).

Morfologisch zien caniene MSC er eveneens uit als spoelvormige cellen die groeien op plastic in een monolaag (de Bakker et al., 2013) (Figuur 6).

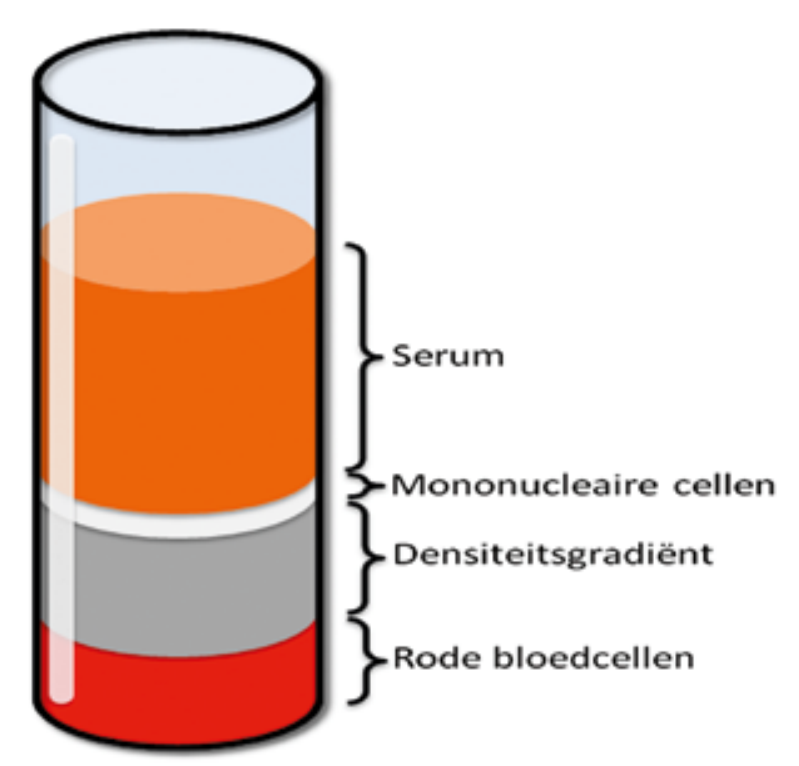

Figuur 5. Overzicht van de verschillende lagen in een beenmergstaal verkregen na centrifugatie met een densiteitsgradiënt (Percoll/Ficoll).

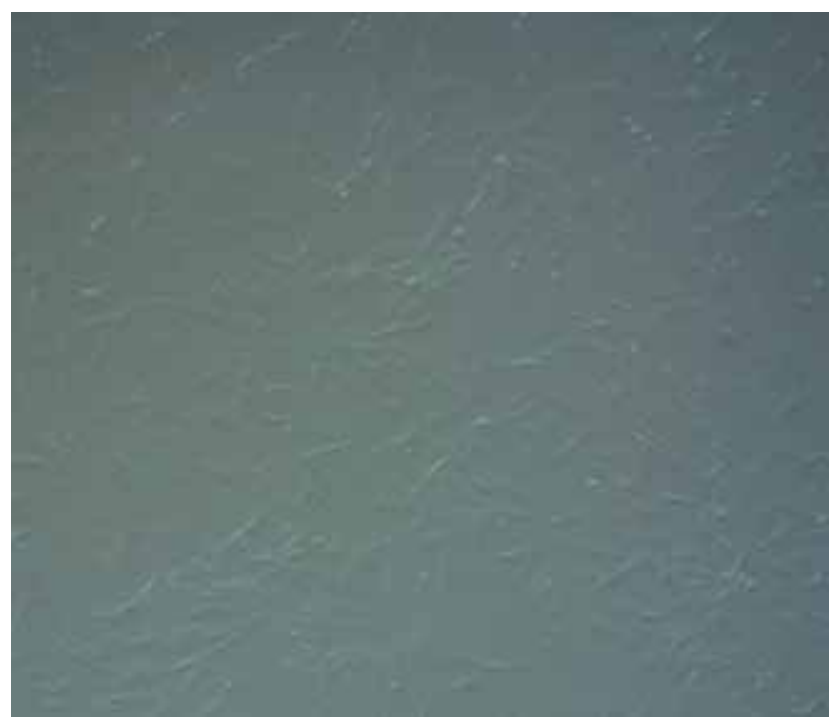

Figuur 6. Morfologisch beeld van beenmerg-afgeleide, caniene MSC. Representatief lichtmicroscopisch beeld van caniene MSC geïsoleerd uit beenmerg. Ongedifferentieerde MSC in cultuur zijn spoelvormige cellen die in een monolaag op de bodem van een cultuurplaat groeien (60x) (de Bakker et al., niet-gepubliceerde data).

De capaciteit van MSC om te differentiëren naar osteogene, chondrogene en adipogene cellijnen is beschreven als een eenduidige karakterisering van MSC (Dominici et al., 2006; De Schauwer et al., 2011). Dit "tri-lineage" differentiatiepotentieel werd reeds door meerdere onderzoeksgroepen aangetoond voor beenmerg- en vet-afgeleide, caniene MSC (Csaki et al., 2007; Vieira et al., 2010; Guercio et al., 2012, Screven et al., 2014). Echter, twee andere studies hebben aangetoond dat geïsoleerde en gecultiveerde caniene MSC moeilijk of zelfs niet konden differentiëren naar de chondro- en de adipogene cellijn (Neupane et al., 2008; Kisiel et al., 2012). Een van deze studies toonde 
de noodzaak aan om het algemeen gebruikte inductiemedium voor de adipogene differentiatie, zoals gebruikt voor humane MSC, te optimaliseren specifiek voor de hond (Neupane et al., 2008). Konijnenserum zou hierbij een kritische stap vormen om adipogenese te induceren bij caniene MSC (Neupane et al., 2008). In de andere studie werd een mislukte differentiatie gerapporteerd van caniene MSC naar de chondrogene cellijn gebaseerd op morfologische en histochemische beoordelingen, ondanks positieve resultaten van andere studies (Kisiel et al., 2012). Om differentiatie naar de chondrogene cellijn te bevestigen, kan in deze gevallen mRNA-expressie van chondrocytmerkers een uitkomst bieden (Vieira et al., 2010).

Het aantonen van de aan- en afwezigheid van specifieke celoppervlakte-antigenen gebeurt door middel van immunofenotypering. Echter, in vergelijking met humane MSC bestaat er nog maar zeer recent een consensus over de immunofenotypering van caniene MSC (Screven et al., 2014). Net zoals bij equine MSC kan deze trage evolutie vooral verklaard worden door een gebrek aan species-specifieke, monoklonale antistoffen voor veterinaire MSC-merkers bij hond en paard; dit in sterk contrast tot bij de mens (De Schauwer et al., 2011; Screven et al., 2014). Screven et al. (2014) hebben aan de hand van de momenteel beschikbare commerciële, caniene antistoffen en via PCR aangetoond voor welke celoppervlakte-antigenen caniene MSC positief zijn en voor welke negatief. Dit is een belangrijke stap voorwaarts voor het op punt stellen van een uniform panel van cellulaire merkers om caniene MSC te definiëren. Toch is dit panel nog niet algemeen in gebruik en is er blijvend nood aan meer gevalideerde monoklonale antistoffen voor specifieke caniene antigenen.

\section{WAT IS DE MEERWAARDE VAN MESEN- CHYMALE STAMCELTHERAPIE?}

Initieel werd de differentiatiecapaciteit van MSC naar andere celtypes als hun belangrijkste therapeutisch nut beschouwd, maar nu worden vooral andere functies toegeschreven aan het therapeutisch succes van MSC (De Schauwer et al., 2013) (Figuur 7).

Een eerste belangrijke functie van MSC is hun immunomodulerend effect, waardoor ze hypo- tot nietimmunogeen voor de gastheer zijn (Barry en Murphy, 2004; Jacobs et al., 2013a). Zo kunnen MSC ontsnappen aan T-celherkenning en kunnen zij de antigeenpresenterende cellen en de "natural killer"-cellen van de gastheer beïnvloeden (Figueroa et al., 2012; Jacobs et al., 2013b). Dit biedt aantrekkelijke mogelijkheden

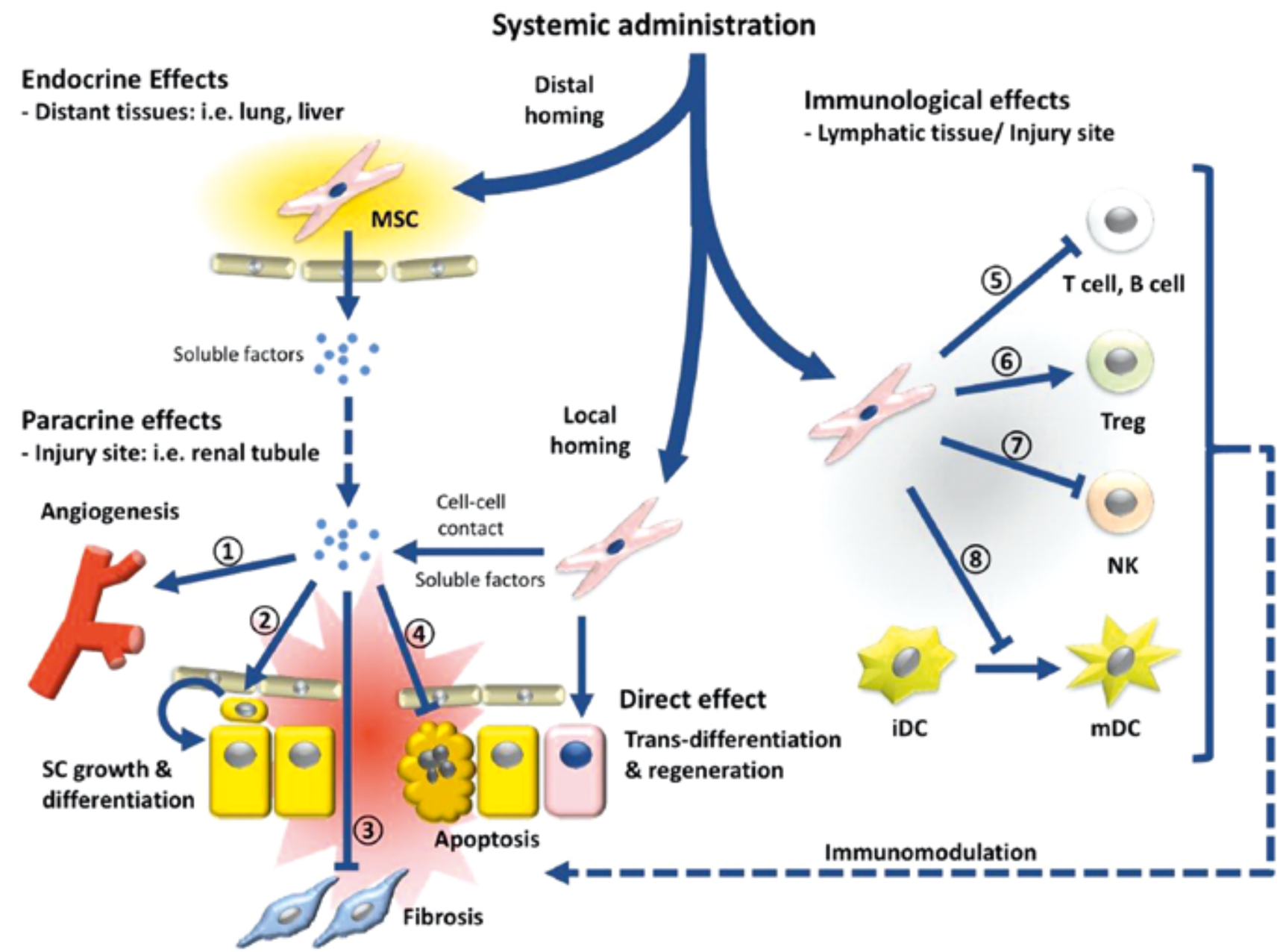

Figuur 7. Systemisch toegediende MSC kunnen systemische (distale endocriene) of lokale (paracriene/cel-celcontact) effecten induceren (overgenomen uit: Figueroa et al., 2012). 
voor allogene MSC-therapie, al dient opgemerkt te worden dat het aantal studies hierover bij de hond zeer beperkt is.

Een tweede belangrijke functie van MSC is hun zogenaamde "homing"-potentieel. MSC migreren, wanneer exogeen toegediend, naar plaatsen waar weefselschade en ontstoken en beschadigde bloedvaten aanwezig zijn (Dimarino et al., 2013). Meerdere studies hebben aangetoond dat MSC chemotactisch worden aangetrokken door ontstekingshaarden, beschadigde cellen, ischemische plaatsen en neoplasieën (Spaeth et al., 2008; Kode et al., 2009; Frisbie en Smith, 2010). Verschillende chemokinen liggen aan de basis van zowel de lokale als de systemische migratie van MSC (Chamberlain et al., 2007).

Eenmaal ter plaatse reageren MSC op hun omgeving via de eigen productie van cytokinen, chemokinen en groeifactoren, tezamen paracriene factoren genoemd (Figueroa et al., 2012). Voorbeelden hiervan zijn "transforming growth factor-alpha" (TGF- $\alpha$ ), TGF- $\beta$ en "vascular endothelial growth factor" (VEGF) (Murphy et al., 2013). Hierdoor kunnen MSC uiteenlopende trofische functies uitoefenen, zoals het redden van apoptotische cellen veroorzaakt door hypoxie, mechanische schade en radiatie; het onderdrukken van de vorming van littekenweefsel; het verminderen van een acuut of chronisch inflammatoir milieu (wat de normale herstelmechanismen van het weefsel tegenwerkt); het stimuleren van angiogenese en neovascularisatie; het uitoefenen van een therapeutisch effect tegen lokale en systemische infecties (antibacterieel effect); het promoten van weefselregeneratie (Borjesson en Peroni, 2011; Dimarino et al., 2013; Murphy et al., 2013). Bovendien zouden exogene MSC via deze paracriene effecten ook endogene stamcellen aanzetten tot differentiatie naar specifieke cellen (Murphy et al., 2013).

\section{HUIDIGE KENNIS VAN STAMCELBEHAN- DELING VOOR ORTHOPEDISCHE INDICA- TIES BIJ DE HOND}

De toepassing van MSC bij de hond was initieel voornamelijk gericht op het therapeutisch testen ervan voor verschillende humane aandoeningen, zoals van het hart en bloedvaten, ruggenmerg, bot en kraakbeen, (de Bakker et al. 2013). De gelijkenissen met betrekking tot de anatomie, pathogenese, atletische prestaties en de grotere gewrichten maken van de hond een beter model voor de mens dan de veelgebruikte rodentia. Bovendien laat de hond een meer gedetailleerde evaluatie van de therapeutische effecten toe (Little en Smith, 2008). Reeds in 1998 onderzochten Bruder et al. het effect van autologe beenmerg-afgeleide MSC op de heling van iatrogene defecten bij caniene femurs (Bruder et al., 1998). De groep honden behandeld met een "carrier" van MSC toonde substantiële nieuwbeenvorming, terwijl er bij de groep honden met onbehandelde femurs een atro- fische "non-union" optrad. Uit deze studie werd geconcludeerd dat deze technologie kon geëxtrapoleerd worden naar de mens, waarbij heling van botdefecten verkregen kon worden via cellen uit het beenmerg van het ilium (Bruder et al., 1998). In een recentere studie werd het effect van intra-articulaire injectie van autologe MSC bestudeerd op de heling van een geinduceerd partieel kraakbeendefect bij proefhonden (Mokbel et al., 2011). Van de 32 gevallen met een gecreëerd kraakbeenletsel werd er bij 8 gevallen geen behandeling ingesteld, 12 gevallen kregen MSC toegediend één dag na het induceren van het letsel en 12 andere gevallen kregen MSC toegediend één maand na het opwekken van het letsel. In vergelijking met de honden van de controlegroep toonden de honden van de twee MSC-behandelde groepen zowel klinisch als histologisch een significant herstel, waarbij de geïnjecteerde stamcellen geïncorporeerd waren in het nieuwgevormde kraakbeen. De conclusie was dat intra-articulaire injectie met MSC een goede optie is voor de behandeling van partiële kraakbeendefecten.

Toch moet opgepast worden met de interpretatie van bovengenoemde resultaten, aangezien gecreëerde letsels niet altijd de aandoeningen bij patiënten adequaat kunnen nabootsen. Ook de resultaten van de studies van MSC-behandeling bij de hond zelf moeten met de nodige voorzichtigheid geïnterpreteerd worden. Ten eerste wordt de studie vaak niet opgezet overeenkomstig de gouden standaard van "evidencebased medicine", namelijk een geblindeerde, gerandomiseerde studie met controlegroepen (De Schauwer et al., 2013). Een dergelijke studie-opzet is in de diergeneeskunde moeilijk vanwege zowel logistieke als economische beperkingen. Het evalueren van de werkzaamheid van MSC-therapie wordt hierdoor bemoeilijkt, zeker wanneer geschikte controlegroepen niet geïncludeerd zijn. Bovendien is de statistische power - zelfs in goed opgezette studies - vaak ontoereikend vanwege het relatief beperkt aantal dieren en de hoge variabiliteit tussen de dieren (heterogene groepen) (De Schauwer et al., 2013). Een bijkomende complicatie is dat in veel studies de behandeling met MSC gecombineerd wordt met diverse biologische factoren, waaronder beenmergsupernatans, autoloog serum en "platelet-rich plasma" (De Schauwer et al., 2013).

Een bijkomend probleem is dat in veel landen, waaronder België, het gebruik van celtherapie bij diergeneeskundige patiënten niet adequaat gecontroleerd wordt door de regulatoire instanties (Fortier en Travis, 2011). In principe wordt het gebruik van stamcellen in de diergeneeskunde op Europees niveau geregeld door een EU-directieve (2001/82/EC) en een regulatie (No 726/2004), waaronder zowel de klassieke als de "cell-based" farmaca vallen. Eenvoudig gesteld betekent dit dat geen enkel veterinair medicinaal product op de EU-markt gebracht mag worden zonder markttoelating. Enkel voor stamcelproducten die geproduceerd worden voor een "single-case"-behandeling of 
Tabel 1. Overzicht van de beschikbare studies in de literatuur van MSC-behandeling van orthopedische aandoeningen bij de hond.

\begin{tabular}{|c|c|c|c|c|c|c|c|}
\hline $\begin{array}{l}\text { Orthopedische } \\
\text { aandoening }\end{array}$ & $\begin{array}{l}\text { Aantal } \\
\text { honden }\end{array}$ & $\begin{array}{l}\text { Heterogene of } \\
\text { homogene groep }\end{array}$ & $\begin{array}{l}\text { Type } \\
\text { behandeling }\end{array}$ & $\begin{array}{l}\text { Controle- } \\
\text { groep }\end{array}$ & Evaluatie & Resultaat & Referentie \\
\hline $\begin{array}{l}\text { Chronische } \\
\text { heupartrose }\end{array}$ & 18 & Heterogeen & $\begin{array}{l}\text { Adipogeen- } \\
\text { afgeleide MSC }\end{array}$ & $\mathrm{Ja}$ & $\begin{array}{l}\text { Klinisch onderzoek } \\
\text { door dierenarts } \\
\text { en antwoord } \\
\text { vragenlijst door } \\
\text { eigenaar op dag } \\
30,60 \text { en } 90 \text { na } \\
\text { behandeling }\end{array}$ & $\begin{array}{l}\text { Statistische } \\
\text { verbetering van } \\
\text { manken, pijn en } \\
\text { "range of motion" } \\
\text { ten opzichte van } \\
\text { controlegroep }\end{array}$ & $\begin{array}{l}\text { Black et al., } \\
2007\end{array}$ \\
\hline $\begin{array}{l}\text { Non-union tibia } \\
\text { Non-union femur } \\
\text { Groot botdefect } \\
\text { distale radius } \\
\text { Non-union carpus } \\
\text { Verlening radius } \\
\text { Botcyste glenoid } \\
\text { Legg-pèrthes-calvé }\end{array}$ & 14 & Heterogeen & $\begin{array}{l}\text { Beenmerg } \\
\text { mononucleaire } \\
\text { cellen } \\
\text { Beenmerg- } \\
\text { afgeleide MSC }\end{array}$ & Nee & $\begin{array}{l}\text { Klinisch onderzoek, } \\
\text { radiografie en } \\
\text { CT-scan op } \\
\text { dag } 0 \text {, dag } 20 \\
\text { en elke maand }\end{array}$ & $\begin{array}{l}\text { Goede botheling } \\
\text { Geen manken } \\
\text { of pijn }\end{array}$ & $\begin{array}{l}\text { Crovace et al., } \\
2008\end{array}$ \\
\hline $\begin{array}{l}\text { Chronische } \\
\text { elleboogartrose }\end{array}$ & 14 & Heterogeen & $\begin{array}{l}\text { Adipogeen- } \\
\text { afgeleide MSC }\end{array}$ & Nee & $\begin{array}{l}\text { Klinisch onderzoek } \\
\text { door dierenarts } \\
\text { en antwoord } \\
\text { vragenlijst door } \\
\text { eigenaar op dag } \\
30,60,90 \text { en } 180 \\
\text { na behandeling }\end{array}$ & $\begin{array}{l}\text { Significante } \\
\text { verbetering } \\
\text { van manken, } \\
\text { pijn en } \\
\text { "range of motion" }\end{array}$ & $\begin{array}{l}\text { Black et al., } \\
2008\end{array}$ \\
\hline $\begin{array}{l}\text { Chronische } \\
\text { elleboogartrose }\end{array}$ & 4 & Heterogeen & $\begin{array}{l}\text { Adipogeen- } \\
\text { afgeleide MSC } \\
\text { met "plateled } \\
\text { riched plasma" } \\
\text { (PRP) } \\
\text { Adipogeen- } \\
\text { afgeleide MSC } \\
\text { met hyaluronzuur }\end{array}$ & Nee & $\begin{array}{l}\text { Klinisch } \\
\text { onderzoek door } \\
\text { dierenarts op } \\
1 \text { week en } \\
1 \text { maand na } \\
\text { behandeling en } \\
\text { antwoord } \\
\text { vragenlijst } \\
\text { door eigenaar }\end{array}$ & $\begin{array}{l}\text { Verbetering } \\
\text { van manken } \\
\text { en pijn }\end{array}$ & $\begin{array}{l}\text { Guercio et al., } \\
2012\end{array}$ \\
\hline $\begin{array}{l}\text { Chronische } \\
\text { heupartrose }\end{array}$ & 8 & Homogeen & $\begin{array}{l}\text { Adipogeen- } \\
\text { afgeleide MSC } \\
\text { met "platelet- } \\
\text { rich plasma" } \\
\text { (PRGF-endoret) }\end{array}$ & $\mathrm{Ja}$ & $\begin{array}{l}\text { Krachtplaat } \\
\text { op dag } 0,30,90 \\
\text { en } 180 \mathrm{na} \\
\text { behandeling }\end{array}$ & $\begin{array}{l}\text { Substantiële } \\
\text { verbetering } \\
\text { van "peak } \\
\text { vertical force" } \\
\text { en "vertical } \\
\text { impulse" } \\
\text { gedurende } \\
\text { volledige follow- } \\
\text { upperiode }\end{array}$ & $\begin{array}{l}\text { Vilar et al., } \\
2013\end{array}$ \\
\hline $\begin{array}{l}\text { Chronische } \\
\text { heupartrose }\end{array}$ & 9 & Homogeen & $\begin{array}{l}\text { Adipogeen- } \\
\text { afgeleide MSC }\end{array}$ & $\mathrm{Ja}$ & $\begin{array}{l}\text { Krachtplaat } \\
\text { op dag } 0,30,90 \\
\text { en } 180 \mathrm{na} \\
\text { behandeling }\end{array}$ & $\begin{array}{l}\text { Significante } \\
\text { verbetering } \\
\text { van "peak } \\
\text { vertical force" } \\
\text { en vertical } \\
\text { impulse" } \\
\text { gedurende }<\text { de } \\
\text { eerste } 3 \text { maanden }\end{array}$ & $\begin{array}{l}\text { Vilar et al., } \\
2014\end{array}$ \\
\hline Heupdysplasie & 9 & Heterogeen & $\begin{array}{l}\text { Vasculaire, } \\
\text { stromale fractie } \\
\text { Adipogeen- } \\
\text { afgeleide MSC }\end{array}$ & Nee & $\begin{array}{l}\text { Klinisch onderzoek } \\
\text { door dierenarts } \\
\text { en antwoord } \\
\text { vragenlijst door } \\
\text { eigenaar op dag } 7 \text {, } \\
15 \text { en } 30 \text { na } \\
\text { behandeling }\end{array}$ & $\begin{array}{l}\text { Duidelijke } \\
\text { klinische } \\
\text { verbetering van } \\
\text { manken, pijn en } \\
\text { "range of motion" }\end{array}$ & $\begin{array}{l}\text { Marx et al., } \\
2014\end{array}$ \\
\hline
\end{tabular}


in het kader van onderzoek moet er geen markttoelating verkregen worden. Alle andere stamcelproducten die op grote schaal geproduceerd worden en/of voor commerciële doeleinden gebruikt worden, moeten eerst officieel geregistreerd worden alvorens ze op de markt gebracht mogen worden. Dit geldt zowel voor autologe als voor allogene stamcelproducten. Markttoelating brengt met zich mee dat enkel stamcelproducten gebruikt worden nadat de veiligheid, steriliteit en werkzaamheid ervan effectief bewezen zijn. Dit is momenteel voor verschillende producten helaas nog niet het geval, wat er reeds toe geleid heeft dat (caniene) MSC toegediend werden bij patiënten zonder dat de werkzaamheid ervan bewezen was in vitro of bij preklinische diermodellen (Fortier en Travis, 2011).

Momenteel zijn er zeven studies naar regeneratieve therapie voor orthopedische indicaties bij honden beschikbaar en deze zijn voornamelijk gericht op het herstel van osteo- en chondrogene defecten met de nadruk op osteoartrose (Black et al., 2007; Black et al., 2008; Crovace et al., 2008; Guercio et al., 2012; Vilar et al., 2013; Marx et al., 2014; Vilar et al., 2014) (Tabel 1). Al deze studies tonen overwegend positieve resultaten, alhoewel er dient opgemerkt te worden dat het resultaat slechts bij twee studies kwantitatief beoordeeld werd door middel van een drukplaat (Vilar et al., 2013; Vilar et al., 2014) (Tabel 1). Bovendien ontbreekt het bij het merendeel van deze studies aan statistische power wegens het lage aantal en de heterogeniteit van de gebruikte honden. Een controleplacebogroep werd slechts in één studie ingesloten (Black et al., 2007). Bijkomend werd de MSC-behandeling in vier van de zeven studies gecombineerd met andere biologische producten.

\section{CONCLUSIE}

Concluderend kan gesteld worden dat het gebruik van MSC bij de hond als alternatieve behandelingsoptie voor verschillende musculoskeletale aandoeningen, zoals osteoartrose, zeker een belangrijk potentieel heeft. Echter, het onduidelijk wettelijk kader en het gebrek aan gefundeerde wetenschappelijke studies hebben ertoe geleid dat stamceltherapie al wijdverspreid bij de hond wordt toegepast, terwijl de efficaciteit en veiligheid nog onvoldoende aangetoond zijn, noch in vitro noch in (pre)klinische studies. Ook het exacte werkingsmechanisme van caniene MSC-therapie in weefselherstel blijft vooralsnog grotendeels onbekend. Al deze aspecten illustreren dan ook de dringende nood aan meer onafhankelijk, academisch onderzoek naar stamceltherapie bij de hond.

\section{REFERENTIES}

Abrams-Ogg A.C., Defarges A., Foster R.A., Bienzle D. (2012). Comparison of canine core bone marrow biopsies from multiple sites using different techniques and needles. Veterinary Clinical Pathology /American Society for Veterinary Clinical Pathology 41, 235-242.

Barry F.P., Murphy J.M. (2004). Mesenchymal stem cells: clinical applications and biological characterization. The International Journal of Biochemistry \& Cell Biology 36, 568-584.

Black L.L., Gaynor J., Adams C., Dhupa S., Sams A.E., Taylor R., Harman S., Gingerich D.A., Harman R. (2008). Effect of intraarticular injection of autologous adipose-derived mesenchymal stem and regenerative cells on clinical signs of chronic osteoarthritis of the elbow joint in dogs. Veterinary Therapy 9, 192-200.

Black L.L., Gaynor J., Gahring D., Adams C., Aron D., Harman S., Gingerich D.A., Harman R. (2007). Effect of adipose-derived mesenchymal stem and regenerative cells on lameness in dogs with chronic osteoarthritis of the coxofemoral joints: a randomized, double-blinded, multicenter, controlled trial. Veterinary Therapy 8, 272284.

Borjesson D.L., Peroni J.F. (2011). The regenerative medicine laboratory: facilitating stem cell therapy for equine disease. Clinics in Laboratory Medicine 31, 109-123.

Bruder S.P., Kraus K.H., Goldberg V.M., Kadiyala S. (1998). The effect of implants loaded with autologous mesenchymal stem cells on the healing of canine segmental bone defects. The Journal of Bone and Joint Surgery America 80, 985-996.

Bruder S.P., Kurth A.A., Shea M., Hayes W.C., Jaiswal N., Kadiyala S. (1998). Bone regeneration by implantation of purified, culture-expanded human mesenchymal stem cells. Journal of Orthopaedic Research 16, 155-162.

Carrade D.D., Affolter V.K., Outerbridge C.A., Watson J.L., Galuppo L.D., Buerchler S., Kumar V., Walker N.J., Borjesson D.L. (2011). Intradermal injections of equine allogeneic umbilical cord-derived mesenchymal stem cells are well tolerated and do not elicit immediate or delayed hypersensitivity reactions. Cytotherapy 13, 11801192.

Chamberlain G., Fox J., Ashton B., Middleton J. (2007). Concise review: mesenchymal stem cells: their phenotype, differentiation capacity, immunological features, and potential for homing. Stem Cells 25, 2739-2749.

Crovace A., Favia A., Lacitignola L., Di Comite M.S., Staffieri F., Francioso E. (2008). Use of autologous bone marrow mononuclear cells and cultured bone marrow stromal cells in dogs with orthopaedic lesions. Veterinary Research Communications 32, S39-44.

Csaki C., Matis U., Mobasheri A., Ye H., Shakibaei M. (2007). Chondrogenesis, osteogenesis and adipogenesis of canine mesenchymal stem cells: a biochemical, morphological and ultrastructural study. Histochemistry and Cell Biology 128, 507-520.

de Bakker E., Van Ryssen B., De Schauwer C., Meyer E. (2013). Canine mesenchymal stem cells: state of the art, perspectives as therapy for dogs and as a model for man. Veterinary Quarterly 33, 225-233.

De Schauwer C., Meyer E., Van de Walle G.R., Van Soom A. (2011). Markers of stemness in equine mesenchymal stem cells: a plea for uniformity. Theriogenology 75, 1431-1443.

De Schauwer C., Van de Walle G.R., Van Soom A., Meyer E. (2013). Mesenchymal stem cell therapy in horses: useful beyond orthopedic injuries? Veterinary Quarterly 33, 234-241.

Dimarino A.M., Caplan A.I., Bonfield T.L. (2013). Mesen- 
chymal stem cells in tissue repair. Frontiers in immuno$\log y$ 4, 201.

Dominici M., Le Blanc K., Mueller I., Slaper-Cortenbach I., Marini F., Krause D., Deans R., Keating A., Prockop D., Horwitz E. (2006). Minimal criteria for defining multipotent mesenchymal stromal cells. The International Society for Cellular Therapy position statement. Cytotherapy $8,315-317$.

Figueroa F.E., Carrion F., Villanueva S., Khoury M. (2012). Mesenchymal stem cell treatment for autoimmune diseases: a critical review. Biological research 45, 269-277.

Fortier L.A. (2005). Stem cells: classifications, controversies, and clinical applications. Veterinary Surgery 34, 415-423.

Fortier L.A., Travis A.J. (2011). Stem cells in veterinary medicine. Stem Cell Research \& Therapy 2, 9.

Frisbie D.D., Smith R.K. (2010). Clinical update on the use of mesenchymal stem cells in equine orthopaedics. Equine Veterinary Journa 42, 86-89.

Gimble J., Guilak F. (2003). Adipose-derived adult stem cells: isolation, characterization, and differentiation potential. Cytotherapy 5, 362-369.

Guercio A., Di Marco P., Casella S., Cannella V., Russotto L., Purpari G., Di Bella S., Piccione G. (2012). Production of canine mesenchymal stem cells from adipose tissue and their application in dogs with chronic osteoarthritis of the humeroradial joints. Cell Biology International 36, 189-194.

Jacobs S.A., Pinxteren J., Roobrouck V.D., Luyckx A., van't Hof W., Deans R., Verfaillie C.M., Waer M., Billiau A.D., Van Gool S.W. (2013a). Human multipotent adult progenitor cells are nonimmunogenic and exert potent immunomodulatory effects on alloreactive T-cell responses. Cell Transplantation 22, 1915-1928.

Jacobs S.A., Roobrouck V.D., Verfaillie C.M., Van Gool S.W. (2013b). Immunological characteristics of human mesenchymal stem cells and multipotent adult progenitor cells. Immunology and Cell Biology 91, 32-39.

Kisiel A.H., McDuffee L.A., Masaoud E., Bailey T.R., Esparza Gonzalez B.P., Nino-Fong R. (2012). Isolation, characterization, and in vitro proliferation of canine mesenchymal stem cells derived from bone marrow, adipose tissue, muscle, and periosteum. The American Journal of Veterinary Research 73, 1305-1317.

Kode J.A., Mukherjee S., Joglekar M.V., Hardikar A.A. (2009). Mesenchymal stem cells: immunobiology and role in immunomodulation and tissue regeneration. Cytotherapy 11, 377-391.

Little C.B., Smith M.M. (2008). Animal models of osteoarthritis. Current Rheumatology Reviews 4, 1-8.

Martinello T., Bronzini I., Maccatrozzo L., Mollo A., Sampaolesi M., Mascarello F., Decaminada M., Patruno M. (2010). Canine adipose-derived-mesenchymal stem cells do not lose stem features after a long-term cryopreservation. Research in Veterinary Science 91, 18-24.

Marx C., Silveira M.D., Beyer Nardi N. (2015). AdiposeDerived Stem Cells in Veterinary Medicine: Characterization and Therapeutic Applications. Stem Cells and Development 4, 1-11.
Marx C., Silveira M.D., Selbach I., da Silva A.S., Braga L.M., Camassola M., Nardi N.B. (2014). Acupoint injection of autologous stromal vascular fraction and allogeneic adipose-derived stem cells to treat hip dysplasia in dogs. Stem Cells International doi: 10.1155/2014/391274, 1-6.

Mokbel A., El-Tookhy O., Shamaa A.A., Sabry D., Rashed L., Mostafa A. (2011). Homing and efficacy of intra-articular injection of autologous mesenchymal stem cells in experimental chondral defects in dogs. Clinical and Experimental Rheumatology 29, 275-284.

Murphy M.B., Moncivais K., Caplan A.I. (2013). Mesenchymal stem cells: environmentally responsive therapeutics for regenerative medicine. Experimental \& Molecular Medicine 45, e54.

Neupane M., Chang C.C., Kiupel M., Yuzbasiyan-Gurkan V. (2008). Isolation and characterization of canine adipose-derived mesenchymal stem cells. Tissue Engineering Part A 14, 1007-1015.

Screven R., Kenyon E., Myers M.J., Yancy H.F., Skasko M., Boxer L., Bigley E.C, Borjesson D.L., Zhu M. (2014). Immunophenotype and gene expression profile of mesenchymal stem cells derived from canine adipose tissue and bone marrow. Veterinary Immunology and Immunopathology 15, 161:21-31.

Spaeth E., Klopp A., Dembinski J., Andreeff M., Marini F. (2008). Inflammation and tumor microenvironments: defining the migratory itinerary of mesenchymal stem cells. Gene Therapy 15, 730-738.

Stewart M.C., Stewart A.A. (2011). Mesenchymal stem cells: characteristics, sources, and mechanisms of action. Veterinary Clinics of North America Equine Practice 27, 243-261.

Takemitsu H., Zhao D., Yamamoto I., Harada Y., Michishita M., Arai T. (2012). Comparison of bone marrow and adipose tissue-derived canine mesenchymal stem cells. BMC Veterinary Research 8, 150.

Vieira N.M., Brandalise V., Zucconi E., Secco M., Strauss B.E., Zatz M. (2010). Isolation, characterization, and differentiation potential of canine adipose-derived stem cells. Cell Transplantation 19, 279-289.

Vilar J.M., Batista M., Morales M., Santana A., Cuervo B., Rubio M., Cugat R., Sopena J., Carrillo J.M. (2014). Assessment of the effect of intraarticular injection of autologous adipose-derived mesenchymal stem cells in osteoarthritic dogs using a double blinded force platform analysis. BMC Veterinary Research 10, 143.

Vilar J.M., Morales M., Santana A., Spinella G., Rubio M., Cuervo B., Cugat R., Carrillo J.M. (2013). Controlled, blinded force platform analysis of the effect of intraarticular injection of autologous adipose-derived mesenchymal stem cells associated to PRGF-Endoret in osteoarthritic dogs. BMC Veterinary Research 9, 131. 